\title{
The past, present, and future of consumer research
}

\author{
Maayan S. Malter ${ }^{1}$ D $\cdot$ Morris B. Holbrook ${ }^{1} \cdot$ Barbara E. Kahn ${ }^{2}$. \\ Jeffrey R. Parker ${ }^{3}$. Donald R. Lehmann ${ }^{1}$
}

Published online: 13 June 2020

(C) Springer Science+Business Media, LLC, part of Springer Nature 2020

\begin{abstract}
In this article, we document the evolution of research trends (concepts, methods, and aims) within the field of consumer behavior, from the time of its early development to the present day, as a multidisciplinary area of research within marketing. We describe current changes in retailing and real-world consumption and offer suggestions on how to use observations of consumption phenomena to generate new and interesting consumer behavior research questions. Consumption continues to change with technological advancements and shifts in consumers' values and goals. We cannot know the exact shape of things to come, but we polled a sample of leading scholars and summarize their predictions on where the field may be headed in the next twenty years.
\end{abstract}

Keywords Consumerbehavior · Information processing · Judgement and decision-making - Consumer culture theory

\section{Introduction}

Beginning in the late 1950s, business schools shifted from descriptive and practitionerfocused studies to more theoretically driven and academically rigorous research (Dahl et al. 1959). As the field expanded from an applied form of economics to embrace theories and methodologies from psychology, sociology, anthropology, and statistics, there was an increased emphasis on understanding the thoughts, desires, and experiences of individual consumers. For academic marketing, this meant that research not only focused on the decisions and strategies of marketing managers but also on the decisions and thought processes on the other side of the market - customers.

Maayan S. Malter

mmalter22@gsb.columbia.edu

1 Columbia Business School, Columbia University, New York, NY, USA

2 The Wharton School, University of Pennsylvania, Philadelphia, PA, USA

3 Department of Marketing, University of Illinois at Chicago, Chicago, IL, USA 
Since then, the academic study of consumer behavior has evolved and incorporated concepts and methods, not only from marketing at large but also from related social science disciplines, and from the ever-changing landscape of real-world consumption behavior. Its position as an area of study within a larger discipline that comprises researchers from diverse theoretical backgrounds and methodological training has stirred debates over its identity. One article describes consumer behavior as a multidisciplinary subdiscipline of marketing "characterized by the study of people operating in a consumer role involving acquisition, consumption, and disposition of marketplace products, services, and experiences" (MacInnis and Folkes 2009, p. 900).

This article reviews the evolution of the field of consumer behavior over the past half century, describes its current status, and predicts how it may evolve over the next twenty years. Our review is by no means a comprehensive history of the field (see Schumann et al. 2008; Rapp and Hill 2015; Wang et al. 2015; Wilkie and Moore 2003, to name a few) but rather focuses on a few key thematic developments. Though we observe many major shifts during this period, certain questions and debates have persisted: Does consumer behavior research need to be relevant to marketing managers or is there intrinsic value from studying the consumer as a project pursued for its own sake? What counts as consumption: only consumption from traditional marketplace transactions or also consumption in a broader sense of non-marketplace interactions? Which are the most appropriate theoretical traditions and methodological tools for addressing questions in consumer behavior research?

\section{A brief history of consumer research over the past sixty years-1960 to 2020}

In 1969, the Association for Consumer Research was founded and a yearly conference to share marketing research specifically from the consumer's perspective was instituted. This event marked the culmination of the growing interest in the topic by formalizing it as an area of research within marketing (consumer psychology had become a formalized branch of psychology within the APA in 1960). So, what was consumer behavior before 1969? Scanning current consumer-behavior doctoral seminar syllabi reveals few works predating 1969, with most of those coming from psychology and economics, namely Herbert Simon's A Behavioral Model of Rational Choice (1955), Abraham Maslow's A Theory of Human Motivation (1943), and Ernest Dichter's Handbook of Consumer Motivations (1964). In short, research that illuminated and informed our understanding of consumer behavior prior to 1969 rarely focused on marketing-specific topics, much less consumers or consumption (Dichter's handbook being a notable exception). Yet, these works were crucial to the rise of consumer behavior research because, in the decades after 1969, there was a shift within academic marketing to thinking about research from a behavioral or decision science perspective (Wilkie and Moore 2003). The following section details some ways in which this shift occurred. We draw on a framework proposed by the philosopher Larry Laudan (1986), who distinguished among three inter-related aspects of scientific inquiry-namely, concepts (the relevant ideas, theories, hypotheses, and constructs); methods (the techniques employed to test and validate these concepts); and aims (the purposes or goals that motivate the investigation). 


\subsection{Key concepts in the late-1960s}

During the late-1960s, we tended to view the buyer as a computer-like machine for processing information according to various formal rules that embody economic rationality to form a preference for one or another option in order to arrive at a purchase decision. This view tended to manifest itself in a couple of conspicuous ways. The first was a model of buyer behavior introduced by John Howard in 1963 in the second edition of his marketing textbook and quickly adopted by virtually every theorist working in our field-including, Howard and Sheth (of course), Engel-Kollat-\&Blackwell, Franco Nicosia, Alan Andreasen, Jim Bettman, and Joel Cohen. Howard's great innovation - which he based on a scheme that he had found in the work of Plato (namely, the linkages among Cognition, Affect, and Conation) - took the form of a boxes-and-arrows formulation heavily influenced by the approach to organizational behavior theory that Howard (University of Pittsburgh) had picked up from Herbert Simon (Carnegie Melon University). The model represented a chain of events

\section{$\mathrm{I} \rightarrow \mathrm{C} \rightarrow \mathrm{A} \rightarrow \mathrm{B} \rightarrow \mathrm{S}$}

where $I=$ inputs of information (from advertising, word-of-mouth, brand features, etc.); $C=$ cognitions (beliefs or perceptions about a brand); $A=$ Affect (liking or preference for the brand); $B=$ behavior (purchase of the brand); and $S=$ satisfaction (post-purchase evaluation of the brand that feeds back onto earlier stages of the sequence, according to a learning model in which reinforced behavior tends to be repeated). This formulation lay at the heart of Howard's work, which he updated, elaborated on, and streamlined over the remainder of his career. Importantly, it informed virtually every buyerbehavior model that blossomed forth during the last half of the twentieth century.

To represent the link between cognitions and affect, buyer-behavior researchers used various forms of the multi-attribute attitude model (MAAM), originally proposed by psychologists such as Fishbein and Rosenberg as part of what Fishbein and Ajzen (1975) called the theory of reasoned action. Under MAAM, cognitions (beliefs about brand attributes) are weighted by their importance and summed to create an explanation or prediction of affect (liking for a brand or preference for one brand versus another), which in turn determines behavior (choice of a brand or intention to purchase a brand). This took the work of economist Kelvin Lancaster (with whom Howard interacted), which assumed attitude was based on objective attributes, and extended it to include subjective ones (Lancaster 1966; Ratchford 1975). Overall, the set of concepts that prevailed in the late-1960s assumed the buyer exhibited economic rationality and acted as a computer-like information-processing machine when making purchase decisions.

\subsection{Favored methods in the late-1960s}

The methods favored during the late-1960s tended to be almost exclusively neopositivistic in nature. That is, buyer-behavior research adopted the kinds of methodological rigor that we associate with the physical sciences and the hypothetico-deductive approaches advocated by the neo-positivistic philosophers of science.

Thus, the accepted approaches tended to be either experimental or survey based. For example, numerous laboratory studies tested variations of the MAAM and focused on 
questions about how to measure beliefs, how to weight the beliefs, how to combine the weighted beliefs, and so forth (e.g., Beckwith and Lehmann 1973). Here again, these assumed a rational economic decision-maker who processed information something like a computer.

Seeking rigor, buyer-behavior studies tended to be quantitative in their analyses, employing multivariate statistics, structural equation models, multidimensional scaling, conjoint analysis, and other mathematically sophisticated techniques. For example, various attempts to test the ICABS formulation developed simultaneous (now called structural) equation models such as those deployed by Farley and Ring $(1970,1974)$ to test the Howard and Sheth (1969) model and by Beckwith and Lehmann (1973) to measure halo effects.

\subsection{Aims in the late-1960s}

During this time period, buyer-behavior research was still considered a subdivision of marketing research, the purpose of which was to provide insights useful to marketing managers in making strategic decisions. Essentially, every paper concluded with a section on "Implications for Marketing Managers." Authors who failed to conform to this expectation could generally count on having their work rejected by leading journals such as the Journal of Marketing Research (JMR) and the Journal of Marketing (JM).

\subsection{Summary-the three $R^{\prime} s$ in the late-1960s}

Starting in the late-1960s to the early-1980s, virtually every buyer-behavior researcher followed the traditional approach to concepts, methods, and aims, now encapsulated under what we might call the three R's - namely, rationality, rigor, and relevance. However, as we transitioned into the 1980s and beyond, that changed as some (though by no means all) consumer researchers began to expand their approaches and to evolve different perspectives.

\subsection{Concepts after 1980}

In some circles, the traditional emphasis on the buyer's rationality - that is, a view of the buyer as a rational-economic, decision-oriented, information-processing, computerlike machine for making choices - began to evolve in at least two primary ways.

First, behavioral economics (originally studied in marketing under the label Behavioral Decision Theory) - developed in psychology by Kahneman and Tversky, in economics by Thaler, and applied in marketing by a number of forward-thinking theorists (e.g., Eric Johnson, Jim Bettman, John Payne, Itamar Simonson, Jay Russo, Joel Huber, and more recently, Dan Ariely) — challenged the rationality of consumers as decision-makers. It was shown that numerous commonly used decision heuristics depart from rational choice and are exceptions to the traditional assumptions of economic rationality. This trend shed light on understanding consumer financial decision-making (Prelec and Loewenstein 1998; Gourville 1998; Lynch Jr 2011) and how to develop "nudges" to help consumers make better decisions for their personal finances (summarized in Johnson et al. 2012). 
Second, the emerging experiential view (anticipated by Alderson, Levy, and others; developed by Holbrook and Hirschman, and embellished by Schmitt, Pine, and Gilmore, and countless followers) regarded consumers as flesh-and-blood human beings (rather than as information-processing computer-like machines), focused on hedonic aspects of consumption, and expanded the concepts embodied by ICABS (Table 1).

\subsection{Methods after 1980}

The two burgeoning areas of research-behavioral economics and experiential theories - differed in their methodological approaches. The former relied on controlled randomized experiments with a focus on decision strategies and behavioral outcomes. For example, experiments tested the process by which consumers evaluate options using information display boards and "Mouselab" matrices of aspects and attributes (Payne et al. 1988). This school of thought also focused on behavioral dependent measures, such as choice (Huber et al. 1982; Simonson 1989; Iyengar and Lepper 2000).

The latter was influenced by post-positivistic philosophers of science-such as Thomas Kuhn, Paul Feyerabend, and Richard Rorty - and approaches expanded to include various qualitative techniques (interpretive, ethnographic, humanistic, and even introspective methods) not previously prominent in the field of consumer research. These included:

Interpretive approaches - such as those drawing on semiotics and hermeneutics - in an effort to gain a richer understanding of the symbolic meanings involved in consumption experiences;

Ethnographic approaches-borrowed from cultural anthropology-such as those illustrated by the influential Consumer Behavior Odyssey (Belk et al. 1989) and its discoveries about phenomena related to sacred aspects of consumption or the deep meanings of collections and other possessions;

Humanistic approaches - such as those borrowed from cultural studies or from literary criticism and more recently gathered together under the general heading of consumer culture theory (CCT);

Table 1 Extended ICABS Framework after 1980

ICABS Explanation

I-information Product categories hitherto neglected by marketing scholars, such as the arts, entertainment, and other cultural offerings.

$C$ - cognitions Various dreams, daydreams, and subconscious thoughts lumped under the headings of "fantasies."

$A$-affect A broader range of emotions such as joy, sorrow, love, hate, fear, anger, attraction, and disgust encompassed under the heading of feelings.

$B$-behavior Forms of consumption that go well beyond purchase commitments, including the expenditure of time as well as money on leisure products, games, playful activities, entertainment, and so forth, under the heading of "fun."

$S$ - satisfaction Consumer value broadly defined and represented by multiple interacted preference experiences (e.g., efficiency, excellence, status, esteem, play, esthetics, ethics, spirituality) 
Introspective or autoethnographic approaches - such as those associated with a method called subjective personal introspection (SPI) that various consumer researchers like Sidney Levy and Steve Gould have pursued to gain insights based on their own private lives.

These qualitative approaches tended not to appear in the more traditional journals such as the Journal of Marketing, Journal of Marketing Research, or Marketing Science. However, newer journals such as Consumption, Markets, \& Culture and Marketing Theory began to publish papers that drew on the various interpretive, ethnographic, humanistic, or introspective methods.

\subsection{Aims after 1980}

In 1974, consumer research finally got its own journal with the launch of the Journal of Consumer Research (JCR). The early editors of JCR-especially Bob Ferber, Hal Kassarjian, and Jim Bettman - held a rather divergent attitude about the importance or even the desirability of managerial relevance as a key goal of consumer studies. Under their influence, some researchers began to believe that consumer behavior is a phenomenon worthy of study in its own right - purely for the purpose of understanding it better. The journal incorporated articles from an array of methodologies: quantitative (both secondary data analysis and experimental techniques) and qualitative. The "right" balance between theoretical insight and substantive relevance-which are not in inherent conflict - is a matter of debate to this day and will likely continue to be debated well into the future.

\subsection{Summary-the three I's after 1980}

In sum, beginning in the early-1980s, consumer research branched out. Much of the work in consumer studies remained within the earlier tradition of the three R's - that is, rationality (an information-processing decision-oriented buyer), rigor (neo-positivistic experimental designs and quantitative techniques), and relevance (usefulness to marketing managers). Nonetheless, many studies embraced enlarged views of the three major aspects that might be called the three I's - that is, irrationality (broadened perspectives that incorporate illogical, heuristic, experiential, or hedonic aspects of consumption), interpretation (various qualitative or "postmodern" approaches), and intrinsic motivation (the joy of pursuing a managerially irrelevant consumer study purely for the sake of satisfying one's own curiosity, without concern for whether it does or does not help a marketing practitioner make a bigger profit).

\section{The present-the consumer behavior field today}

\subsection{Present Concepts}

In recent years, technological changes have significantly influenced the nature of consumption as the customer journey has transitioned to include more interaction on digital platforms that complements interaction in physical stores. This shift poses a 
major conceptual challenge in understanding if and how these technological changes affect consumption. Does the medium through which consumption occurs fundamentally alter the psychological and social processes identified in earlier research? In addition, this shift allows us to collect more data at different stages of the customer journey, which further allows us to analyze behavior in ways that were not previously available.

Revisiting the ICABS framework, many of the previous concepts are still present, but we are now addressing them through a lens of technological change (Table 2). In recent years, a number of concepts (e.g., identity, beliefs/lay theories, affect as information, self-control, time, psychological ownership, search for meaning and happiness, social belonging, creativity, and status) have emerged as integral factors that influence and are influenced by consumption. To better understand these concepts, a number of influential theories from social psychology have been adopted into consumer behavior research. Self-construal (Markus and Kitayama 1991), regulatory focus (Higgins 1998), construal level (Trope and Liberman 2010), and goal systems (Kruglanski et al. 2002) all provide social-cognition frameworks through which consumer behavior researchers study the psychological processes behind consumer behavior. This "adoption" of social psychological theories into consumer behavior is a symbiotic relationship that further enhances the theories. Tory Higgins happily stated that he learned more about his own theories from the work of marketing academics (he cited Angela Lee and Michel Pham) in further testing and extending them.

\subsection{Present Methods}

Not only have technological advancements changed the nature of consumption but they have also significantly influenced the methods used in consumer research by adding both new sources of data and improved analytical tools (Ding et al. 2020). Researchers continue to use traditional methods from psychology in empirical research (scale development, laboratory experiments, quantitative analyses, etc.) and interpretive approaches in qualitative research. Additionally, online experiments using participants

Table 2 ICABS framework in the digital age

\begin{tabular}{|c|c|}
\hline ICABS & Explanation \\
\hline$I$-information & $\begin{array}{l}\text { Consumers get their get information from different source-social media, peer to peer reviews, } \\
\text { and websites for every product and have access to far more information (admittedly of } \\
\text { greatly varying degrees of veracity) than before. }\end{array}$ \\
\hline$C$ - cognitions & $\begin{array}{l}\text { How does technology impact consumer cognition. For instance, attention is divided more } \\
\text { than ever across our myriad devices and multi-tasking is the norm for most people. }\end{array}$ \\
\hline$A$-affect & $\begin{array}{l}\text { Increasing effective polarity and stark mood swings arising from the combination of (1) } \\
\text { never-ending streams of media and news exposing consumers to very positive and } \\
\text { negative ideas and events and (2) the increased prevalence of confirmation biases arising } \\
\text { from "fake" sources/news. }\end{array}$ \\
\hline$B$-behavior & $\begin{array}{l}\text { The consequences for moral/ethical actions and perceptions of outsourcing decisions and } \\
\text { responsibilities to technology, the replacement of intimate interpersonal relation sips of } \\
\text { relationships with one's phone, online game person/ avatar, and the like. }\end{array}$ \\
\hline$S$-satisfaction & $\begin{array}{l}\text { The dramatic shift in satisfaction from a personal to a shared experience, industries, and firms } \\
\text { (e.g., Yelp) built solely on markets of consumer satisfaction ratings. }\end{array}$ \\
\hline
\end{tabular}


from panels such as Amazon Mechanical Turk and Prolific have become commonplace in the last decade. While they raise concerns about the quality of the data and about the external validity of the results, these online experiments have greatly increased the speed and decreased the cost of collecting data, so researchers continue to use them, albeit with some caution. Reminiscent of the discussion in the 1970s and 1980s about the use of student subjects, the projectability of the online responses and of an increasingly conditioned "professional" group of online respondents (MTurkers) is a major concern.

Technology has also changed research methodology. Currently, there is a large increase in the use of secondary data thanks to the availability of Big Data about online and offline behavior. Methods in computer science have advanced our ability to analyze large corpuses of unstructured data (text, voice, visual images) in an efficient and rigorous way and, thus, to tap into a wealth of nuanced thoughts, feelings, and behaviors heretofore only accessible to qualitative researchers through laboriously conducted content analyses. There are also new neuro-marketing techniques like eyetracking, fMRI's, body arousal measures (e.g., heart rate, sweat), and emotion detectors that allow us to measure automatic responses. Lastly, there has been an increase in large-scale field experiments that can be run in online B2C marketplaces.

\subsection{Present Aims}

Along with a focus on real-world observations and data, there is a renewed emphasis on managerial relevance. Countless conference addresses and editorials in JCR, JCP, and other journals have emphasized the importance of making consumer research useful outside of academia - that is, to help companies, policy makers, and consumers. For instance, understanding how the "new" consumer interacts over time with other consumers and companies in the current marketplace is a key area for future research. As global and social concerns become more salient in all aspects of life, issues of longterm sustainability, social equality, and ethical business practices have also become more central research topics. Fortunately, despite this emphasis on relevance, theoretical contributions and novel ideas are still highly valued. An appropriate balance of theory and practice has become the holy grail of consumer research.

The effects of the current trends in real-world consumption will increase in magnitude with time as more consumers are digitally native. Therefore, a better understanding of current consumer behavior can give us insights and help predict how it will continue to evolve in the years to come.

\section{The future-the consumer behavior field in $2040^{1}$}

Niels Bohr once said, "Prediction is very difficult, especially if it's about the future." Indeed, it would be a fool's errand for a single person to hazard a guess about the state of the consumer behavior field twenty years from now. Therefore, predictions from 34 active consumer researchers were collected to address this task. Here, we briefly summarize those predictions.

\footnotetext{
${ }^{1}$ The other papers use 2030 as a target year but we asked our survey respondents to make predictions for 2040 and thus we have a different future target year.
} 


\subsection{Future Concepts}

While few respondents proffered guesses regarding specific concepts that would be of interest twenty years from now, many suggested broad topics and trends they expected to see in the field. Expectations for topics could largely be grouped into three main areas. Many suspected that we will be examining essentially the same core topics, perhaps at a finer-grained level, from different perspectives or in ways that we currently cannot utilize due to methodological limitations (more on methods below). A second contingent predicted that much research would center on the impending crises the world faces today, most mentioning environmental and social issues (the COVID-19 pandemic had not yet begun when these predictions were collected and, unsurprisingly, was not anticipated by any of our respondents). The last group, citing the widely expected profound impact of AI on consumers' lives, argued that AI and other technology-related topics will be dominant subjects in consumer research circa 2040 .

While the topic of technology is likely to be focal in the field, our current expectations for the impact of technology on consumers' lives are narrower than it should be. Rather than merely offering innumerable conveniences and experiences, it seems likely that technology will begin to be integrated into consumers' thoughts, identities, and personal relationships - probably sooner than we collectively expect. The integration of machines into humans' bodies and lives will present the field with an expanding list of research questions that do not exist today. For example, how will the concepts of the self, identity, privacy, and goal pursuit change when web-connected technology seamlessly integrates with human consciousness and cognition? Major questions will also need to be answered regarding philosophy of mind, ethics, and social inequality. We suspect that the impact of technology on consumers and consumer research will be far broader than most consumer-behavior researchers anticipate.

As for broader trends within consumer research, there were two camps: (1) those who expect (or hope) that dominant theories (both current and yet to be developed) will become more integrated and comprehensive and (2) those who expect theoretical contributions to become smaller and smaller, to the point of becoming trivial. Both groups felt that current researchers are filling smaller cracks than before, but disagreed on how this would ultimately be resolved.

\subsection{Future Methods}

As was the case with concepts, respondents' expectations regarding consumer-research methodologies in 2030 can also be divided into three broad baskets. Unsurprisingly, many indicated that we would be using many technologies not currently available or in wide use. Perhaps more surprising was that most cited the use of technology such as AI, machinelearning algorithms, and robots in designing - as opposed to executing or analyzing experiments. (Some did point to the use of technologies such as virtual reality in the actual execution of experiments.) The second camp indicated that a focus on reliable and replicable results (discussed further below) will encourage a greater tendency for preregistering studies, more use of "Big Data," and a demand for more studies per paper (versus more papers per topic, which some believe is a more fruitful direction). Finally, the third lot indicated that "real data" would be in high demand, thereby necessitating the use 
of incentive-compatible, consequential dependent variables and a greater prevalence of field studies in consumer research.

As a result, young scholars would benefit from developing a "toolkit" of methodologies for collecting and analyzing the abundant new data of interest to the field. This includes (but is not limited to) a deep understanding of designing and implementing field studies (Gerber and Green 2012), data analysis software (R, Python, etc.), text mining and analysis (Humphreys and Wang 2018), and analytical tools for other unstructured forms of data such as image and sound. The replication crisis in experimental research means that future scholars will also need to take a more critical approach to validity (internal, external, construct), statistical power, and significance in their work.

\subsection{Future Aims}

While there was an air of existential concern about the future of the field, most agreed that the trend will be toward increasing the relevance and reliability of consumer research. Specifically, echoing calls from journals and thought leaders, the respondents felt that papers will need to offer more actionable implications for consumers, managers, or policy makers. However, few thought that this increased focus would come at the expense of theoretical insights, suggesting a more demanding overall standard for consumer research in 2040. Likewise, most felt that methodological transparency, open access to data and materials, and study pre-registration will become the norm as the field seeks to allay concerns about the reliability and meaningfulness of its research findings.

\subsection{Summary - Future research questions and directions}

Despite some well-justified pessimism, the future of consumer research is as bright as ever. As we revised this paper amidst the COVID-19 pandemic, it was clear that many aspects of marketplace behavior, consumption, and life in general will change as a result of this unprecedented global crisis. Given this, and the radical technological, social, and environmental changes that loom on the horizon, consumer researchers will have a treasure trove of topics to tackle in the next ten years, many of which will carry profound substantive importance. While research approaches will evolve, the core goals will remain consistent - namely, to generate theoretically insightful, empirically supported, and substantively impactful research (Table 3).

\section{Conclusion}

At any given moment in time, the focal concepts, methods, and aims of consumerbehavior scholarship reflect both the prior development of the field and trends in the larger scientific community. However, despite shifting trends, the core of the field has remained constant-namely, to understand the motivations, thought processes, and experiences of individuals as they consume goods, services, information, and other offerings, and to use these insights to develop interventions to improve both marketing strategy for firms and consumer welfare for individuals and groups. Amidst the excitement of new technologies, social trends, and consumption experiences, it is important to look back and remind ourselves of the insights the field has already 
Table 3 Future consumer behavior research questions

Future research questions

1. How does the new generation of consumers differ from past generations?

2. Where do consumers go for information and how do they weight information from different sources?

3. What values drive consumer decisions?

4. What do consumers expect from retailers?

5. How have computational advances changed the retailer-consumer relationship?

6. What implications do these changes have for personal data privacy and security?

7. How will major global shifts change how and what we consume?
Explanation

Consumers are digitally native; many enact purchase behavior through their mobile phones first.

Consumers rely more on social media for their information; so, brands must learn how to promote through those channels, which include bloggers and influencers. Given the digitally connected world, peer-to-peer evaluations and reviews are increasingly influential in preference formation, perceptions, and choice.

Consumers have increasing concern about sustainability, healthy lifestyles, and fair labor practices - in sum, social responsibility - factors that have a growing influence on their purchase decisions. This means that although consumers remain brand loyal, they are now loyal to different brands from those favored by previous generations.

Consumers think about retailers as an omni-channel entity. They expect seamless integration of information and marketing across all channels - brick-and-mortar, online, and mobile.

Omni-channel retailing creates "Big Data," which more sophisticated retailers can and do use to personalize and customize the shopping experience. By using machine learning and artificial intelligence (AI), marketers can predict consumers' attitudes and, in turn, recommend products based on individual preferences. Savvy marketers can mix a consumer's past behavior with information from other consumers and expert advice in making recommendations. Recommendation systems have greatly changed the shopping journey in that consumers are offered "ideal" options without having to search. This technological advancement also allows consumer researchers to study the customer experiences during the whole customer journey, and not just on product transactions.

Discourse over answering this question is and will remain a critical central debate between policy-makers, firms, and individuals in the years to come.

The COVID-19 pandemic is still unfolding, but we already see that it will have a major impact on every aspect of life. We are just beginning to see how it is affecting consumption during the crisis and can only take wild guesses as to what its long-term influence will be. Now that the world is so interconnected, this and other global events can have impacts that drive change in consumer behavior. 
generated. Effectively integrating these past findings with new observations and fresh research will help the field advance our understanding of consumer behavior.

\section{References}

Beckwith, N. E., \& Lehmann, D. R. (1973). The importance of differential weights in multiple attribute models of consumer attitude. Journal of Marketing Research, 10(2), 141-145.

Belk, R. W., Wallendorf, M., \& Sherry Jr., J. F. (1989). The sacred and the profane in consumer behavior: theodicy on the odyssey. Journal of Consumer Research, 16(1), 1-38.

Dahl, R. A., Haire, M., \& Lazarsfeld, P. F. (1959). Social science research on business: product and potential. New York: Columbia University Press.

Ding, Y., DeSarbo, W. S., Hanssens, D. M., Jedidi, K., Lynch Jr., J. G., \& Lehmann, D. R. (2020). The past, present, and future of measurements and methods in marketing analysis. Marketing Letters, https://oi. org/10.1007/s11002-020-09527-7.

Farley, J. U., \& Ring, L. W. (1970). An empirical test of the Howard-Sheth model of buyer behavior. Journal of Marketing Research, 7(4), 427-438.

Farley, J. U., \& Ring, L. W. (1974). "Empirical” specification of a buyer behavior model. Journal of Marketing Research, 11(1), 89-96.

Fishbein, M., \& Ajzen, I. (1975). Belief, attitude, intention, and behavior: an introduction to theory and research. Reading: Addison-Wesley.

Gerber, A. S., \& Green, D. P. (2012). Field experiments: design, analysis, and interpretation. New York: WW Norton.

Gourville, J. T. (1998). Pennies-a-day: the effect of temporal reframing on transaction evaluation. Journal of Consumer Research, 24(4), 395-408.

Higgins, E. T. (1998). Promotion and prevention: regulatory focus as a motivational principle. Advances in Experimental Social Psychology, 30, 1-46.

Howard, J. A., \& Sheth, J. (1969). The theory of buyer behavior. New York: Wiley.

Huber, J., Payne, J. W., \& Puto, C. (1982). Adding asymmetrically dominated alternatives: violations of regularity and the similarity hypothesis. Journal of Consumer Research, 9(1), 90-98.

Humphreys, A., \& Wang, R. J. H. (2018). Automated text analysis for consumer research. Journal of Consumer Research, 44(6), 1274-1306.

Iyengar, S. S., \& Lepper, M. R. (2000). When choice is demotivating: can one desire too much of a good thing? Journal of Personality and Social Psychology, 79(6), 995-1006.

Johnson, E. J., Shu, S. B., Dellaert, B. G., Fox, C., Goldstein, D. G., Häubl, G., et al. (2012). Beyond nudges: tools of a choice architecture. Marketing Letters, 23(2), 487-504.

Kruglanski, A. W., Shah, J. Y., Fishbach, A., Friedman, R., Chun, W. Y., \& Sleeth-Keppler, D. (2002). A theory of goal systems. Advances in Experimental Social Psychology, 34, 311-378.

Lancaster, K. (1966). A new theory of consumer behavior. Journal of Political Economy, 74, 132-157.

Laudan, L. (1986). Methodology's prospects. In PSA: Proceedings of the Biennial Meeting of the Philosophy of Science Association, 1986(2), 347-354.

Lynch Jr., J. G. (2011). Introduction to the journal of marketing research special interdisciplinary issue on consumer financial decision making. Journal of Marketing Research, 48(SPL) Siv-Sviii.

MacInnis, D. J., \& Folkes, V. S. (2009). The disciplinary status of consumer behavior: a sociology of science perspective on key controversies. Journal of Consumer Research, 36(6), 899-914.

Markus, H. R., \& Kitayama, S. (1991). Culture and the self: implications for cognition, emotion, and motivation. Psychological Review, 98(2), 224-253.

Payne, J. W., Bettman, J. R., \& Johnson, E. J. (1988). Adaptive strategy selection in decision making. Journal of Experimental Psychology: Learning, Memory, and Cognition, 14(3), 534-552.

Prelec, D., \& Loewenstein, G. (1998). The red and the black: mental accounting of savings and debt. Marketing Science, 17(1), 4-28.

Rapp, J. M., \& Hill, R. P. (2015). Lordy, Lordy, look who's 40! The Journal of Consumer Research reaches a milestone. Journal of Consumer Research, 42(1), 19-29.

Ratchford, B. T. (1975). The new economic theory of consumer behavior: an interpretive essay. Journal of Consumer Research, 2(2), 65-75. 
Schumann, D. W., Haugtvedt, C. P., \& Davidson, E. (2008). History of consumer psychology. In Haugtvedt, C. P., Herr, P. M., \& Kardes, F. R. eds. Handbook of consumer psychology (pp. 3-28). New York: Erlbaum.

Simonson, I. (1989). Choice based on reasons: the case of attraction and compromise effects. Journal of Consumer Research, 16(2), 158-174.

Trope, Y., \& Liberman, N. (2010). Construal-level theory of psychological distance. Psychological Review, $117(2), 440-463$.

Wang, X., Bendle, N. T., Mai, F., \& Cotte, J. (2015). The journal of consumer research at 40: a historical analysis. Journal of Consumer Research, 42(1), 5-18.

Wilkie, W. L., \& Moore, E. S. (2003). Scholarly research in marketing: exploring the "4 eras" of thought development. Journal of Public Policy \& Marketing, 22(2), 116-146.

Publisher's note Springer Nature remains neutral with regard to jurisdictional claims in published maps and institutional affiliations. 